\title{
Defining the Northeast Monsoon of India
}

\author{
VASUBANDHU MISRA \\ Center for Ocean-Atmospheric Prediction Studies, and Department of Earth, Ocean and Atmospheric Science, \\ and Florida Climate Institute, Florida State University, Tallahassee, Florida
}

AMIT BHARDWAJ

Center for Ocean-Atmospheric Prediction Studies, and Florida Climate Institute, Florida State University, Tallahassee, Florida

(Manuscript received 14 August 2018, in final form 31 December 2018)

\begin{abstract}
This study introduces an objective definition for onset and demise of the northeast Indian monsoon (NEM). The definition is based on the land surface temperature analysis over the Indian subcontinent. It is diagnosed from the inflection points in the daily anomaly cumulative curve of the area-averaged surface temperature over the provinces of Andhra Pradesh, Rayalseema, and Tamil Nadu located in the southeastern part of India. Per this definition, the climatological onset and demise dates of the NEM season are 6 November and 13 March, respectively. The composite evolution of the seasonal cycle of $850-\mathrm{hPa}$ winds, surface wind stress, surface ocean currents, and upper-ocean heat content suggest a seasonal shift around the time of the diagnosed onset and demise dates of the NEM season. The interannual variations indicate onset date variations have a larger impact than demise date variations on the seasonal length, seasonal anomalies of rainfall, and surface temperature of the NEM. Furthermore, it is shown that warm El Niño-Southern Oscillation (ENSO) episodes are associated with excess seasonal rainfall, warm seasonal land surface temperature anomalies, and reduced lengths of the NEM season. Likewise, cold ENSO episodes are likely to be related to seasonal deficit rainfall anomalies, cold land surface temperature anomalies, and increased lengths of the NEM season.
\end{abstract}

\section{Introduction}

The northeast Indian monsoon (NEM) season is usually defined by the calendar months of October-December (OND), when there is significant rainfall in the southeastern part of peninsular India (Srinivasan and Ramamurthy 1973; Dhar and Rakhecha 1983; Raj and Jamadar 1990; Sontakke 1993; Singh and Sontakke 1999). Therefore, in defining the NEM season, the focus is on the seasonality of the rainfall in that area (http://www.imdchennai.gov. in/northeast_monsoon.htm). In contrast to the southwest Indian summer monsoon (SISM), the NEM contributes only about $11 \%$ of the all-India annual rainfall (Rajeevan et al. 2012). However, the NEM contributes anywhere between $30 \%$ and $60 \%$ of the annual mean in the provinces of Tamil Nadu, coastal Andhra Pradhesh, and Rayalseema (see Fig. 1a; Rajeevan et al. 2012). Thus, the NEM seasonal rainfall affects the productivity of rice and maize in the provinces of Tamil Nadu and Andhra

\footnotetext{
Corresponding author: Vasubandhu Misra, vmisra@fsu.edu
}

Pradesh (Krishnakumar et al. 2004; Samui et al. 2013). That said, the NEM rainfall displays significant variations at intraseasonal (Rajeevan et al. 2012; Dimri et al. 2016), interannual (Ramaswamy 1972; Dhar and Rakhecha 1983; Singh and Sontakke 1999; Kripalani and Kumar 2004; Sreekala et al. 2012; Rajeevan et al. 2012; Dimri et al. 2016), and longer time scales (Zubair and Ropelewski 2006; Kumar et al. 2007; Dimri et al. 2016). Furthermore, it has been noted that climate models simulate the mean state and the variability of the NEM rainfall rather poorly (Rodwell 2005; Rajeevan et al. 2012; Siew et al. 2014). For example, Rajeevan et al. (2012) indicated in an analysis of seasonal hindcasts from multiple contemporary coupled climate models that the NEM seasonal mean rainfall is grossly underestimated and there is no skill in predicting its interannual anomalies, even at zero month lead. Similarly, Siew et al. (2014) showed that a majority of the models in phase 5 of the Coupled Model Intercomparison Project (CMIP5) had a large bias of the Southeast Asian winter monsoon precipitation with a display of erroneously weak interannual variations. 

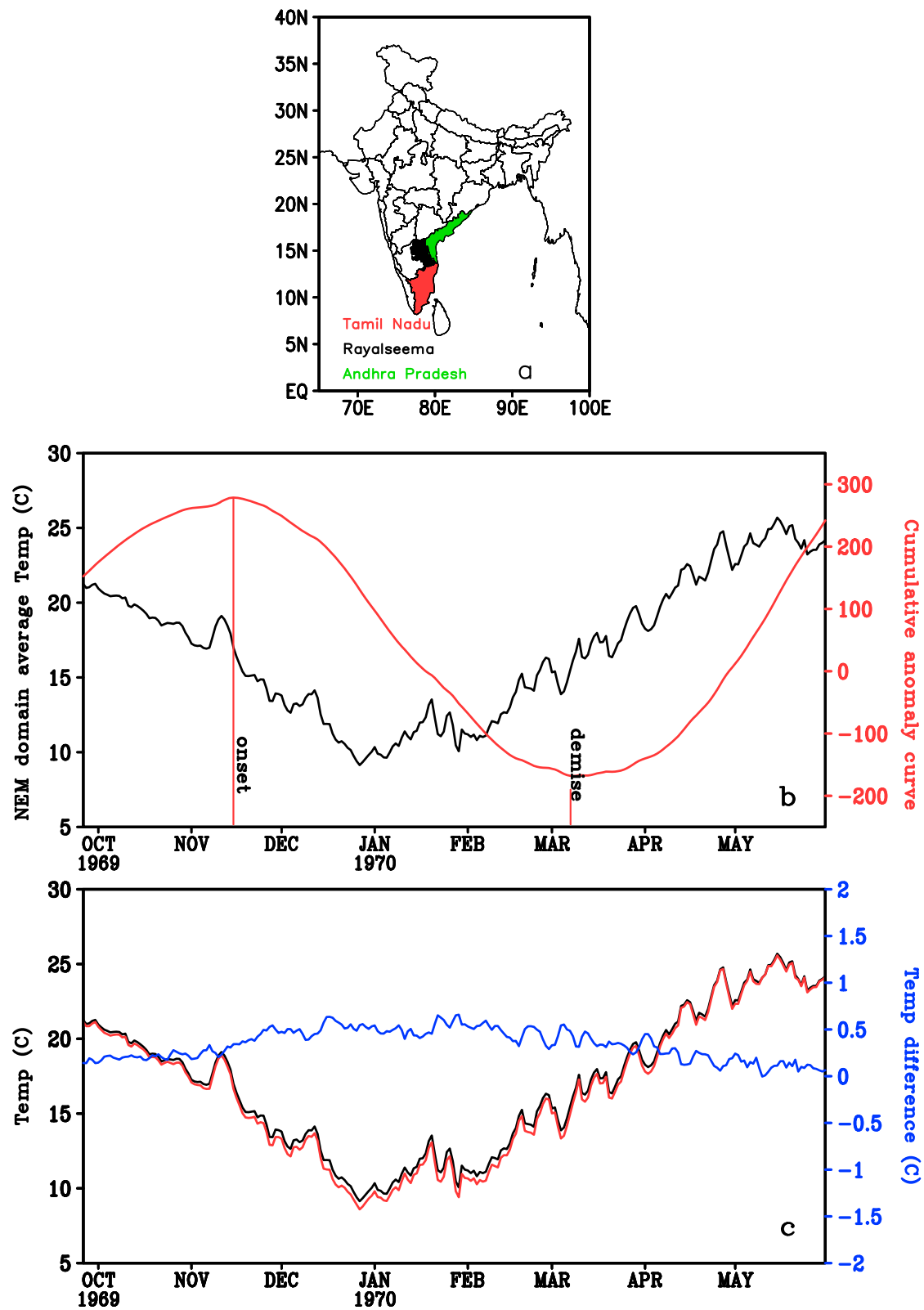

FIG. 1. (a) The NEM domain [shaded area covering provinces of Tamil Nadu (shaded in red), Rayalseema (black), and Andhra Pradesh (green) in southern India]. (b) Illustration of the onset (15 Nov) and demise (8 Mar) of the NEM for 1969/70 [the black curve is the daily surface temperature averaged over the NEM domain between demise of the previous year (1969) and onset of the following year (1970) Indian summer monsoon, and the red curve is the corresponding cumulative anomaly curve]. (c) The daily averaged surface temperature $\left({ }^{\circ} \mathrm{C}\right)$ over the NEM domain (black) and all of India averaged (red) for 1969/70 NEM season and their corresponding differences (blue).

A majority of the earlier studies on the NEM have used the fixed 3-month period of OND to define the NEM season (Krishna Rao and Jagannathan 1953; Srinivasan and Ramamurthy 1973; Dhar and Rakhecha 1983; Krishnan 1984; Raj and Jamadar 1990; Sontakke 1993; Singh and Sontakke 1999; Kripalani and Kumar 2004).
But while fixing the length of the season to a calendar season such as OND has obvious convenience for conducting diagnostic studies of the NEM, it could potentially lead to erroneous conclusions or limit our understanding of the NEM variations in cases where the seasonal length displays significant variations. 
There are several reasons to pay close attention to the variability and the seasonal evolution of the surface temperature in the NEM season. First, the surface temperature over India displays a robust seasonal cycle (Krishnamurti et al.1976; Yanai et al. 1992). Therefore, it can be leveraged to detect the onset and demise of seasons.

Second, Ingole et al. (2012) indicated that children five years old or younger are particularly susceptible to cold temperatures during the NEM season. It may be noted that significant parts of northern India periodically get to near-freezing temperatures between dusk-to-dawn hours during the boreal winter season. Similarly, Ingole et al. (2017) indicated a higher cold-related mortality of elderly individuals in rural India. Furthermore, Basu (2009) reported the confounding factor of air pollutants is not clearly stated in many of the human epidemiological studies. From recent media coverage, it has been well documented that pollution in northern India during the NEM season is a huge factor in air quality and has been termed as a serious risk to human health (https://www. vox.com/energy-and-environment/2017/11/22/16666808/ india-air-pollution-new-delhi; Carmichael et al. 2009). Pollutants remain suspended in the air for a considerable period of time as a result of the prevalent largescale subsidence that persists with a low-level inversion and cold surface temperature during the NEM season (Krishnamurti et al. 1997).

Third, the prevalence and range of disease vectors including microbes are sensitive to both temperature and rainfall (Eurowinter Group 1997; Randolph and Rogers 2010), which raises the risk to human and crop health when changes in these variables occur. Furthermore, the Eurowinter Group (1997) suggested that cerebrovascular and respiratory diseases increase significantly for every $1^{\circ} \mathrm{C}$ fall in temperature below $18^{\circ} \mathrm{C}$.

The fourth factor to be considered is cold stress and its effect on rice cultivation. The optimum temperature for rice cultivation is between $25^{\circ}$ and $35^{\circ} \mathrm{C}$ (Ghadirnezhad and Fallah 2014). Rice is a cold-sensitive plant that is the most widely consumed staple food, especially in Asia (Bishwajit et al. 2013). Low temperatures can cause serious yield losses of rice (Farrell et al. 2006). While rice is grown in the boreal winter, summer, and autumn seasons, winter rice or kharif rice is the leading rice crop accounting for a major portion of the total acreage under rice during all seasons in the country (Pandey and Tiwari 2012; http://lcweb2.loc.gov/frd/cs/). It is important to note that self-sufficiency in rice production is paramount to food security for the region (Bishwajit et al. 2013).

In light of these factors, defining the NEM season solely based on rainfall is rather limited in application and potentially ignores the far-reaching detrimental factors of varying surface temperature during the NEM season. Nonetheless, a majority of the studies conducted on the NEM season have focused on rainfall variations (Dhar and Rakhecha 1983; Sontakke 1993; Rajeevan et al. 2012; Dimri et al. 2016).

In this paper, we introduce a new objective methodology to define the start and end dates of the NEM based on surface temperature values rather than rainfall. We demonstrate that this definition of the NEM is consistent with the seasonal cycles of upper-air and some upperocean variables and encompasses the rainy part of the NEM season, as well. We also discuss the interannual variations of this newly defined NEM season with global sea surface temperature (SST) variations, focusing on the teleconnection of the NEM variations with the El Niño-Southern Oscillation (ENSO) variations in the tropical Pacific Ocean.

\section{Data and methodology}

Defining the NEM is based on a similar methodology used for defining the SISM (Noska and Misra 2016). However, a major difference in the two definitions is that we focus on rainfall for the SISM and surface temperature for the NEM. This choice of different variables in the definition of onset/demise of the SISM and NEM will be explained after the methodology is described below.

In Noska and Misra (2016), the onset/demise of the SISM was based on the inflection points of the daily cumulative anomaly curve of the all-India averaged rainfall. The day after the minimum and maximum in the daily cumulative anomaly curve of the all-India averaged rainfall was defined as the onset and demise of the SISM, respectively.

The NEM domain follows from the Indian Meteorological Department's definition, which includes the provinces of Rayalseema, coastal Andhra Pradesh, and Tamil Nadu as depicted in Fig. 1a. Here, we use the surface temperature analysis following Srivastava et al. (2009) to determine the daily area average surface temperature $T$ for the NEM region. These data are available as a gridded analysis at $1^{\circ} \times 1^{\circ}$ grid resolution based on surface air temperature observations of maximum and minimum temperature taken from around 550 surface stations in India over 37 years (1969 to 2005). We then compute the climatological mean of the area average surface temperature $T_{\text {clim }}$ from the minimum temperature $T_{\min }$ analysis using the days of the year outside of the SISM season. For illustration purposes in Fig. 1b, we show the time series of $T_{\min }$ for a particular year (1969/70) in the intervening period from the demise of the previous SISM season (25 September 1969) and onset of the next SISM season (1 June 1970). The dates for the onset and demise of the SISM are obtained from Noska and Misra (2016). 
The daily anomalies of the surface temperature $T^{\prime}$ are then computed as

$$
T^{\prime}=T_{\min }-T_{\text {clim }}
$$

The cumulative anomaly (CA) curve for the $m$ th (Julian) day of the $k$ th year is then computed as

$$
\mathrm{CA}_{k}(m)=\sum_{i=n}^{m} T_{k}^{\prime}(i)
$$

where $n$ is the day after the demise of the preceding SISM season. The CA curve for 1969/70 is shown in Fig. $1 \mathrm{~b}$ for days between the demise of SISM in 1969 and onset of SISM in 1970. The inflection points of the maximum (minimum) in the CA curve then serve as the onset and demise of the NEM season. For example, for the 1969/70 NEM season, the onset and demise dates were determined to be 15 November and 8 March, respectively. These inflection points suggest that the onset date of the NEM in Fig. 1b is the first day of the year after the demise of the SISM, when the surface temperature over the NEM domain is lower than the climatological mean computed between the demise of the previous SISM and onset of the following SISM. Similarly, the demise date of the NEM shown in Fig. $1 \mathrm{~b}$ is the first day of the year, when the surface temperature anomaly over the NEM domain exceeds the climatological mean of the surface temperature between the demise of the previous SISM and onset of the following SISM. Note that the difference in the all-India and NEM domain mean surface temperature is negligible (Fig. 1c). We also find that using the CA curve with either of the two domains' (NEM or all-India) averaged surface temperature yields identical onset and demise dates for the NEM season. Therefore, there is consistency in using the onset and demise dates of the SISM based on allIndia average rainfall and then using domain-averaged surface temperature over the NEM region for the diagnosis of onset and demise of the NEM season.

It is important to compute the CA curve between the demise of the preceding and onset of the following SISM season in order to isolate the onset and demise dates within the boreal winter and spring seasons. Otherwise, including the surface temperature for the rest of the days in the year leads to unrealistic onset and demise dates of the NEM season as a result of the CA curve overlapping with the SISM season in boreal summer and fall seasons. It also becomes clear, from the analysis presented in the following section, why we avoid the use of rainfall for defining the onset and demise of the NEM. We make use of the Climate Forecast System Reanalysis (CFSR; Saha et al. 2010) to make composites of upper-air and upper-ocean variables, and these are presented in the following section. Henceforth, the NEM season will refer to the varying seasonal length from one year to the next unless otherwise stated.

\section{Results}

\section{a. Seasonal variations of lower-tropospheric variables}

The climatological mean rainfall for the NEM season is illustrated in Fig. 2a, which shows that the three provinces of the NEM domain-Tamil Nadu, Rayalseema, and Andhra Pradesh-receive the most rainfall in southern peninsular India. Some parts of northeast and northern India (Kashmir) also display mean winter monsoon rainfall of similar magnitude as that over the NEM domain. Similarly, the climatological NEM seasonal mean surface temperature is shown in Fig. 2b. The average climatological temperature in a majority of the region over India is in the range of $21^{\circ}-25^{\circ} \mathrm{C}$ except for parts of Kashmir in northern India and parts of southwestern India, where the temperatures are below $20^{\circ} \mathrm{C}$.

The daily climatological time series of rainfall over the NEM region in Fig. 2c shows that, although November is the peak season of rainfall, there is a smooth transition from the boreal summer to winter months. As a result, it becomes very difficult to objectively distinguish SISM demise from onset of the NEM season if rainfall is used as the metric.

The variability of the rainfall in the boreal winter months over the NEM domain is very large (Fig. 2d). The coefficient of variation $\left(C_{v}=\right.$ standard deviation/mean) for NEM seasonal rainfall with varying seasonal length is $45.7 \%$ (Table 1). However, the NEM seasonal rainfall for the fixed 3-month season of OND is $28.9 \%$. This clearly indicates that variations in the length of the NEM season are an important consideration that should not be ignored. The relatively much higher $C_{v}$ of the NEM seasonal rainfall in comparison to the corresponding surface temperature in Fig. 2d (and Table 1) reveals the problem with using rainfall as a variable to define the NEM season. It would be difficult to get a robust estimate of the seasonal mean climatology of the NEM rainfall given the high degrees of variation, a consequence of which is that the CA curve based on daily rainfall anomaly varies significantly from year to year. Therefore, the diagnosis of onset and demise of the NEM season using daily rainfall becomes inconsistent from year to year, as inflection points in the corresponding CA curve can sometimes unrealistically reside in the premonsoon showers of the SISM (typically in the months of April and May, not shown). Therefore, even though the climatological rain over the NEM region in January, February, and into 

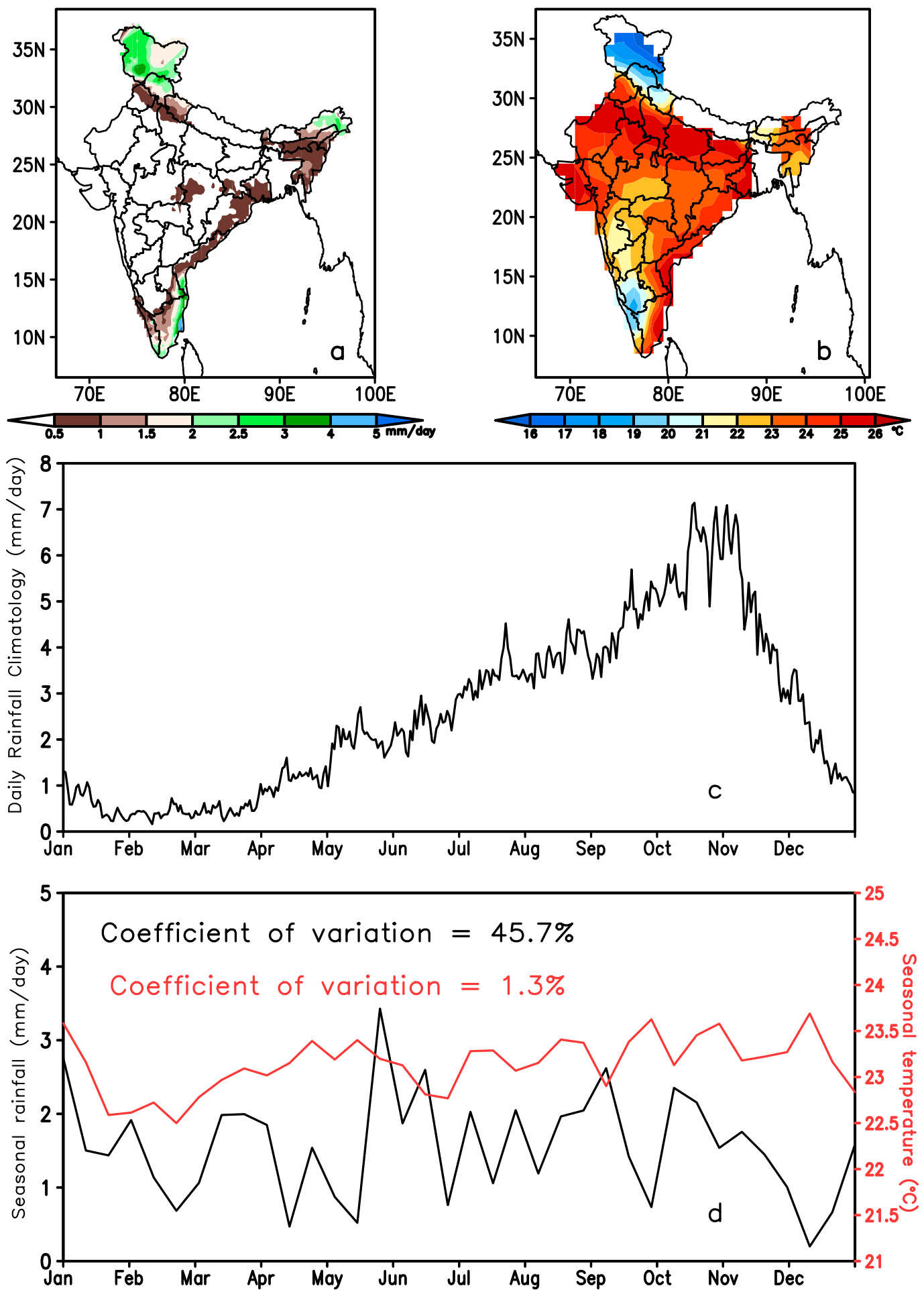

FIG. 2. The climatological seasonal mean $\operatorname{NEM}$ (a) rainfall $\left(\mathrm{mm}_{\text {day }}{ }^{-1}\right)$ and (b) surface temperature $\left({ }^{\circ} \mathrm{C}\right)$. (c) The climatological time series of daily rainfall over the NEM domain $\left(\mathrm{mm} \mathrm{day}^{-1}\right)$. (d) The time series of NEM seasonal mean rainfall (black; $\mathrm{mm} \mathrm{day}^{-1}$ ) and surface temperature (red; ${ }^{\circ} \mathrm{C}$ ) with their coefficient of variations indicated in their respective colors. 
TABLE 1. Details of coefficient of variations of seasonal mean variables.

\begin{tabular}{lccc}
\hline \multicolumn{1}{c}{ Variable } & Coefficient of variation $C_{v}$ & Standard deviation $\sigma$ & Seasonal mean climatology $m$ \\
\hline NEM OND mean precipitation & $28.9 \%$ & $1.23 \mathrm{~mm} \mathrm{day}^{-1}$ & $4.25 \mathrm{~mm} \mathrm{day}^{-1}$ \\
NEM OND mean surface temperature & $3.6 \%$ & $0.55^{\circ} \mathrm{C}$ & $15.06^{\circ} \mathrm{C}$ \\
NEM variable length of the season & $45.7 \%$ & $0.71 \mathrm{~mm} \mathrm{day}^{-1}$ & $1.56 \mathrm{~mm} \mathrm{day}^{-1}$ \\
mean precipitation & & & $0.3^{\circ} \mathrm{C}$ \\
NEM variable length of the season & $1.3 \%$ & & $23.14^{\circ} \mathrm{C}$ \\
mean surface temperature & & \\
\hline
\end{tabular}

mid-March is minimal (Fig. 2c), it still constitutes part of the NEM season as defined in this paper on account of the seasonality displayed by the surface temperature. It should be noted that the $C_{v}$ of NEM seasonal surface temperature for varying seasonal length as indicated in Fig. $2 \mathrm{~d}$ (and Table 1 ) is $1.3 \%$, which is lower than the $3.6 \%$ for the corresponding fixed 3-month OND seasonal mean anomaly. This low $C_{v}$ of seasonal mean surface temperature yet again emphasizes the advantage of using seasonal surface temperature with a varying seasonal length as a metric to define the NEM season.

Table 1 also reveals some other interesting benefits of considering a varying seasonal length of the NEM season. First and foremost, the standard deviation of the seasonal mean variables of precipitation and surface temperature reduces by considering the varying seasonal length of the NEM season compared to the fixed 3-month OND season. Second, the seasonal mean climatology of precipitation also reduces in a varying length of the NEM season compared to the fixed 3-month NEM season while the seasonal mean surface temperature increases in a varying length of the NEM season compared to the fixed 3-month NEM season.
These differences are expected given that our definition of the NEM season invariably extends the traditional OND season significantly into the early boreal spring season.

The distinction between the SISM and NEM seasons using the definitions proposed in Noska and Misra (2016) for the former and in this paper for the latter is most apparent in Fig. 3. The more commonly utilized JuneSeptember (JJAS) seasonal mean for SISM and OND for NEM, although convenient, is arbitrarily and erroneously assigning the monsoon seasons to calendar months when the transition between the seasons can be variable (Fig. 3). It should be noted that the climatological onset and demise of the NEM season is 6 November and 13 March, respectively, as compared to the climatological onset and demise of the SISM season, which is 5 June and 7 October (Noska and Misra 2016).

The composite of the surface temperature and $850-\mathrm{hPa}$ wind pattern evolution five days prior to onset and postonset of the NEM season is shown in Figs. 4a-c. As stated earlier, the all-India and NEM domains' averaged temperature variations are alike, and therefore, the transition from the preonset (Fig. 4a) to postonset (Fig. 4c) period of

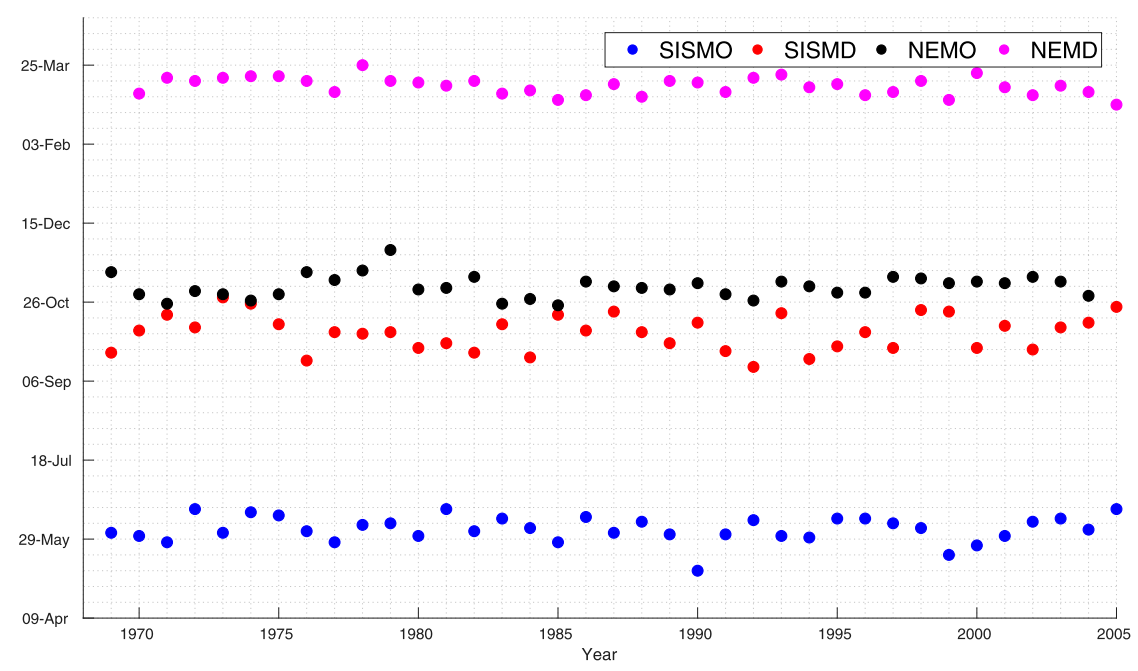

FIG. 3. The time series of the onset of the SISM (SISMO), demise of the SISM (SISMD), onset of the NEM (NEMO), and demise of the NEM (NEMD). 

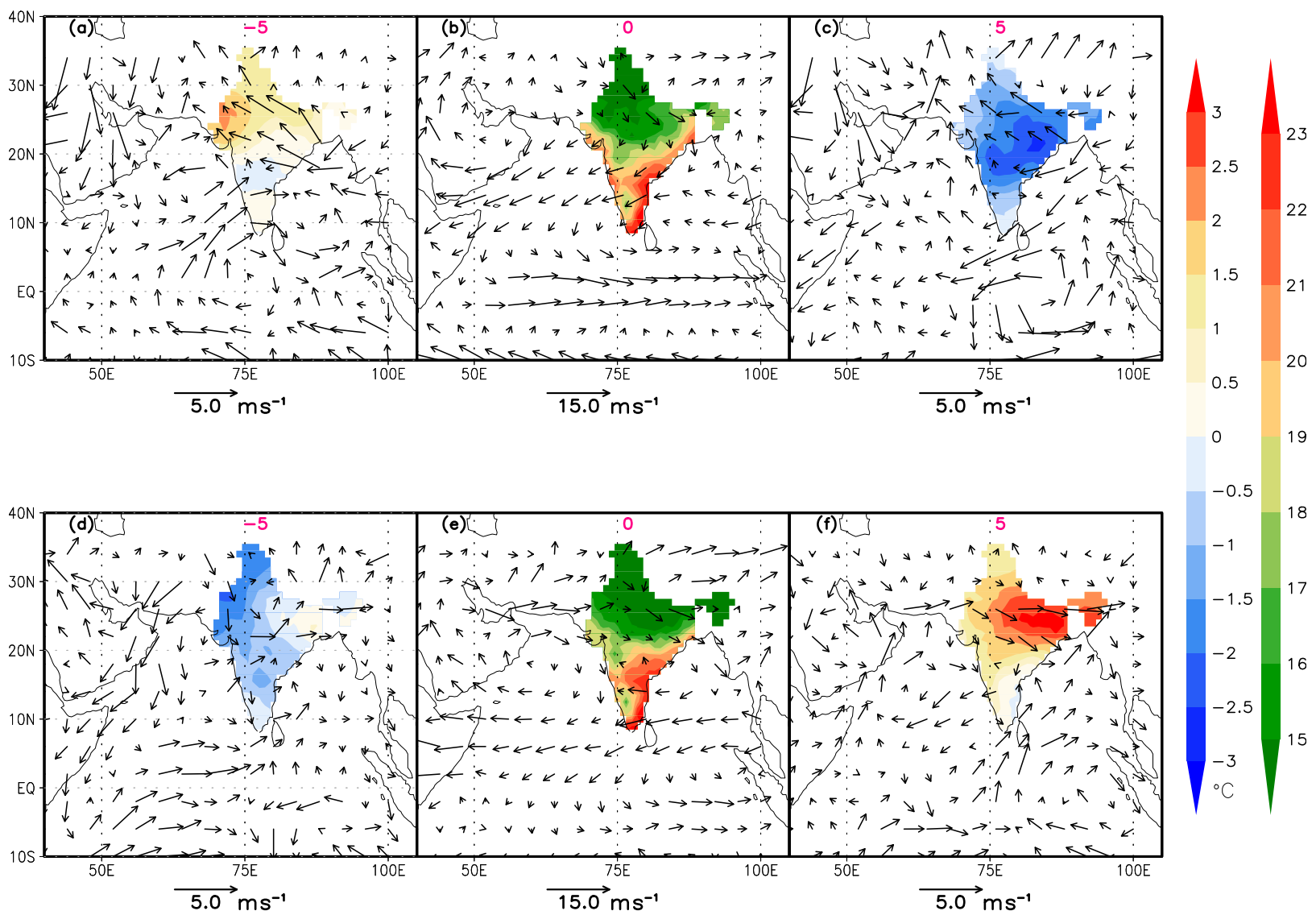

FIG. 4. The climatological composite of surface air temperature over India $\left({ }^{\circ} \mathrm{C}\right)$ overlaid with $850-\mathrm{hPa}$ winds $\left(\mathrm{m} \mathrm{s}^{-1}\right)$ at time of (b) onset and (e) demise of the NEM. The differences of the composites at 5 days (a) prior and (c) postonset (day 0) of the NEM season with respect to the corresponding composite fields at the time of onset is also shown. Similarly, the differences of the composites at 5 days (d) prior and (f) postdemise (day 0) of the NEM season with respect to the corresponding fields at time of demise is also shown.

the NEM is apparent across India as the temperatures drop after the onset day (day 0; Fig. 4b). The 850-hPa wind pattern in Fig. $4 \mathrm{~b}$ suggests that the Arabian Sea and southern peninsular India is dominated by cyclonic flow at the time of onset of the NEM (day 0). Furthermore, in the buildup to the onset of the NEM season, the magnitude of the wind speed in the Somali jet shown at $850 \mathrm{hPa}$ peaks (Fig. 4b). This is discerned by comparing the corresponding daily anomalies with respect to the day of onset, which are of opposite signs around the Gulf of Oman, five days prior to onset (Fig. 4a) and five days postonset (Fig. 4c). In addition, it is also apparent that the northeasterly flow (within which the Somali jet resides) is also shifted southward by the time of onset of the NEM season (Fig. 4b) relative to five days prior to the onset of the NEM (Fig. 4a).

Similarly, the composites centered around the time of the demise of the NEM shows the increase in surface temperature across India from the predemise to postdemise period (Figs. 4d-f). Likewise, the changes of the
850-hPa winds are easily discernible, with the anticyclonic flow over the Arabian Sea amplifying from the predemise to postdemise period (Figs. 4d-f). In addition, the easterly flow over the Bay of Bengal also diminishes in strength from the predemise to postdemise period (Figs. 4d-f), while the northeasterly flow over the Arabian Sea is weakened considerably postdemise of the NEM (Figs. 4d-f). Krishnamurti et al. (1976) showed that the Somali jet responds to a multitude of factors including the presence of topography over Madagascar and eastern Africa (i.e., the beta effect and the landocean thermal contrast). In fact, they conclude that the Somali jet is most sensitive to the land-ocean thermal contrast. Therefore, these composite evolutions of lowlevel winds reflect the consistency and representative nature of the index in representing the NEM evolution.

As noted earlier, the seasonal evolution of the establishment of the Siberian-Mongolian high and its outflow, which forms the low-level northeasterly flow of the NEM, is also evident from the reversal of the mean sea level 

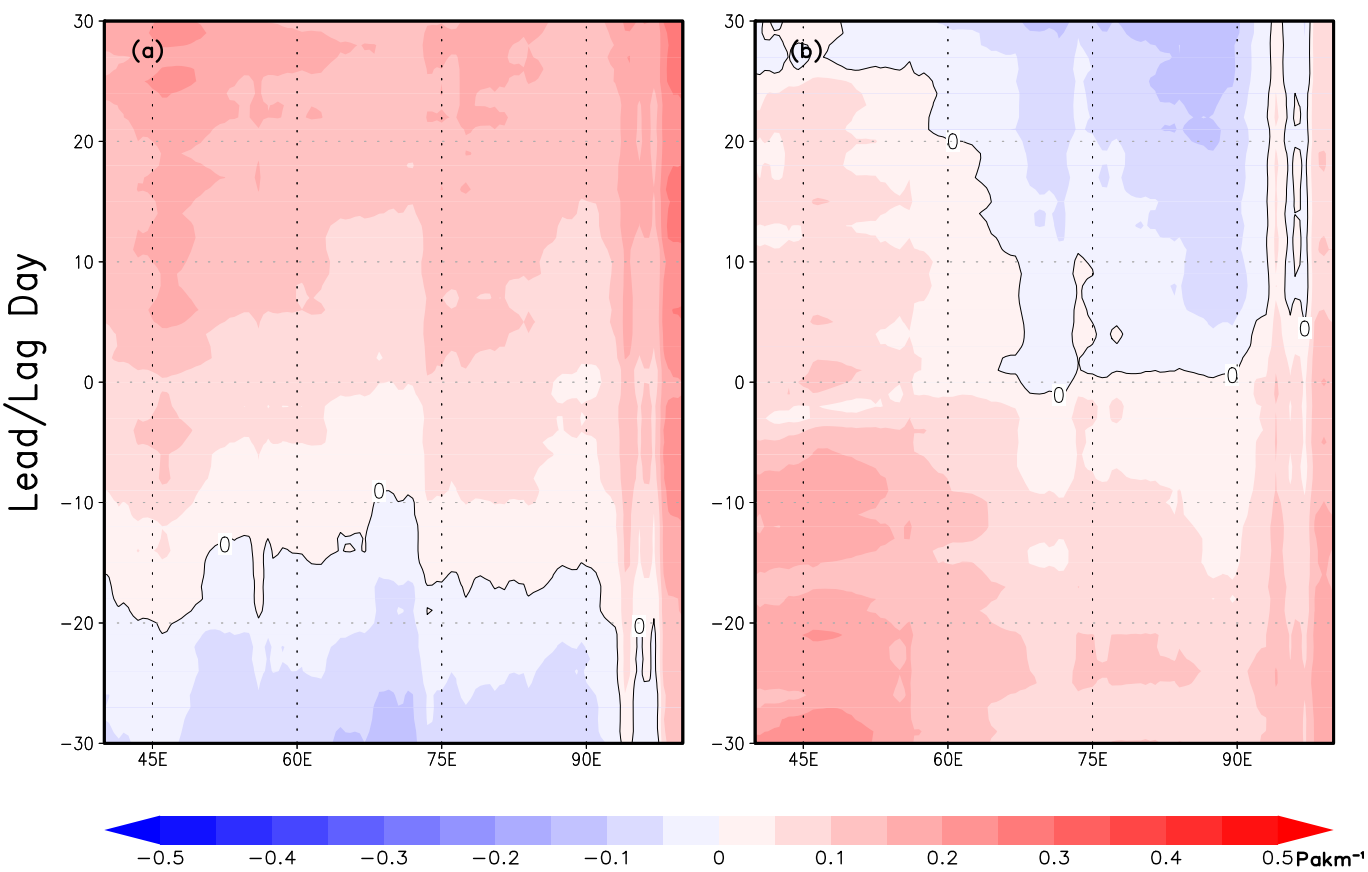

FIG. 5. The climatological daily meridional MSLP gradient $\left(\mathrm{hPa} \mathrm{km}^{-1}\right)$ between $25^{\circ} \mathrm{N}$ and $5^{\circ} \mathrm{S}$ as a function of lead/lag time (in days) with respect to (a) onset (day 0) and (b) demise (day 0) date of the NEM. For (a), positive (negative) values on the $y$ axis refer to the meridional MSLP gradient lagging (leading) the onset date of the NEM. Similarly, in (b), positive (negative) values on the $y$ axis refer to the meridional MSLP gradient leading (lagging) the demise date of the NEM.

pressure (MSLP) gradient. This is illustrated in the form of composites of the gradient in the MSLP computed as the difference between $25^{\circ} \mathrm{N}$ and $5^{\circ} \mathrm{S}$ as a function of lead/lag with the onset (Fig. 5a) and demise (Fig. 5b) date of the NEM season. In Fig. 5a, we find that in the time range of 10-20 days before the diagnosed onset of the NEM season, the MSLP gradient has shifted from negative to positive values nearly uniformly across a wide span of longitudes $\left(40^{\circ}-90^{\circ} \mathrm{E}\right)$. This is consistent with the evolution of the 850-hPa winds in Figs. $4 \mathrm{a}-\mathrm{c}$, which indicate establishment of the northeasterly flow well before the onset of the NEM season. These lowlevel northeasterlies seem to modulate in strength around the time of onset, but the Siberian-Mongolian high is already established by day 0 (onset) of the NEM season. On the other hand, Fig. 5b shows a clear zonal progression in the reversal of the MSLP gradient in going from western to eastern longitudes $\left(40^{\circ}-90^{\circ} \mathrm{E}\right)$. For example, the negative MSLP gradient in the $40^{\circ}$ to $72^{\circ} \mathrm{E}$ range appears to show a rapid change in the reversal of MSLP gradient with longitude. This pattern of MSLP gradient reversal with longitude around the demise date of the NEM season suggests a shrinking and eastwardreceding Siberian-Mongolian high. The comparison between Figs. 5a and 5b illustrate the asymmetry between the seasonal evolution of the Siberian-Mongolian high around the onset period and its devolution around the demise of the NEM season.

\section{b. Seasonal variations of upper-ocean variables}

The tropical northern Indian Ocean is unique in that its western boundary current evolves with seasonal reversal of directions from southwest to northeast during the SISM and NEM seasons, respectively. Similarly, the equatorial winds over the Indian Ocean include semiannual occurrence of eastward winds from April to June and October to November, which make it considerably warmer than other equatorial oceans (Schott and McCreary 2001; Beal et al. 2013). Consequently, it is well known that the SST and the heat content in the northern Indian Ocean increases from the boreal winter to the next spring (Pan and Oort 1990; Tourre and White 1995; Schott and McCreary 2001). Therefore, it is worthwhile to compare the evolution of the upper-ocean variables in the tropical Indian Ocean with the diagnosed time of onset and demise of the NEM season.

The diagnosis of the onset of the NEM does seem to capture the inflections of the seasonal cycle of some of the upper-ocean variables (Fig. 6). The wind stress and its curl in Fig. 6b suggest that the Arabian Sea is dominated by positive cyclonic curl at day 0 (time of onset). The wind stress shows that the Somali jet is 

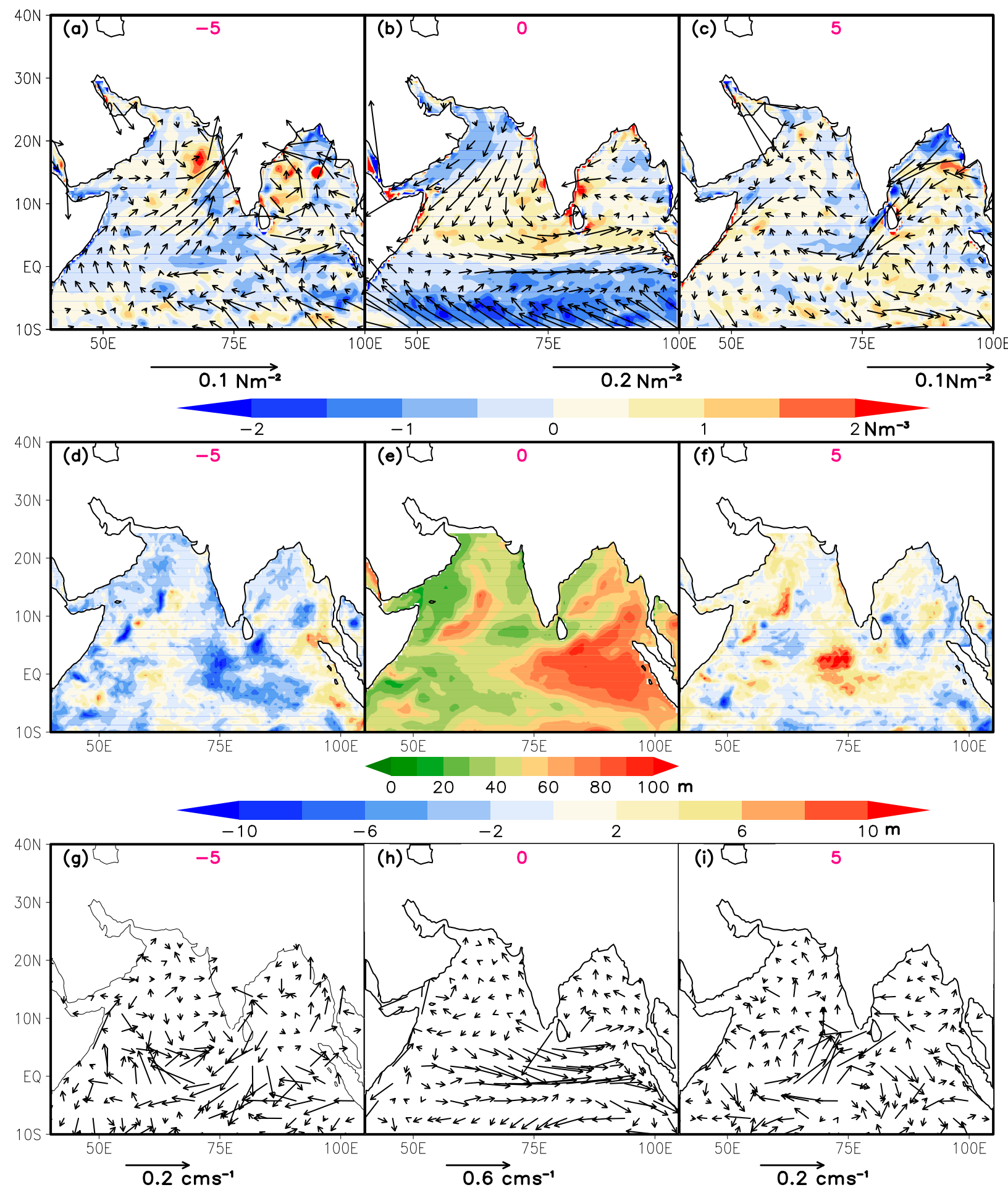

FIG. 6. The climatological composite of (b) wind stress $\left(\mathrm{N} \mathrm{m}^{-2}\right)$ and $\operatorname{curl}\left(\mathrm{N} \mathrm{m}^{-3}\right)$, (e) heat content as measured by the depth of the $26^{\circ} \mathrm{C}$ isotherm $(\mathrm{m})$, and $(\mathrm{h})$ surface ocean currents $\left(\mathrm{cm} \mathrm{s}^{-1}\right)$ on the day of onset of the NEM (day 0$)$. The differences of the composites at 5 days (a),(d),(g) prior and (c),(f),(i) postonset (day 0) of the NEM season with respect to the corresponding fields on day of onset is shown for (a),(c) wind stress $\left(\mathrm{N} \mathrm{m}^{-2}\right)$ and curl $\left(\mathrm{N} \mathrm{m}^{-3}\right),(\mathrm{d}),(\mathrm{f})$ heat content $(\mathrm{m})$, and $(\mathrm{g})$, (i) surface currents $\left(\mathrm{cm} \mathrm{s}^{-1}\right)$. 

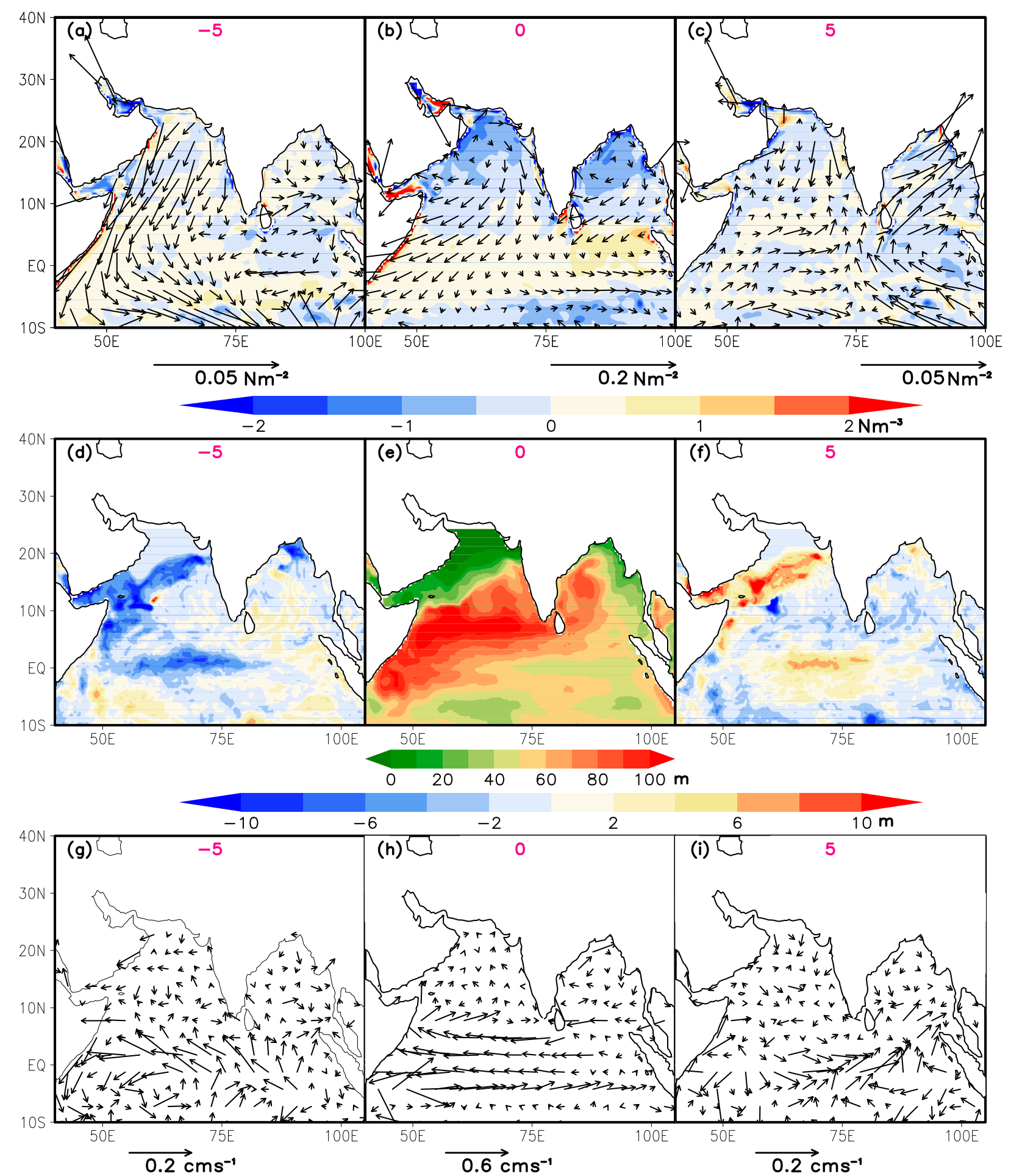

FIG. 7. As in Fig. 6, but for the demise of the NEM.

mature at the day of onset (Fig. 6b) with the anomalies five days prior to onset being slightly weaker (Fig. 6a) and postonset (Fig. 6c) being slightly stronger along the Somali coast and along the Gulf of Oman. Furthermore, the heat content anomalies (measured as the depth of the $26^{\circ} \mathrm{C}$ isotherm) build up over the western Arabian Sea and equatorial Indian Ocean from five days prior (Fig. 6d) through the day of onset (Fig. 6e) of the NEM 
TABLE 2. Correlations of NEM season parameters. Here, $\mathrm{O}, \mathrm{D}, \mathrm{L}, \mathrm{R}$, and $\mathrm{T}$ as the last letter in the acronyms refer to onset, demise, length, seasonal rainfall anomaly, and seasonal surface temperature anomaly of the NEM and SISM seasons, respectively. Boldface values are statistically significant at $90 \%$ confidence interval according to $t$ test.

\begin{tabular}{lcccrr}
\hline \hline Variables & NEML & NEMD & SISMO & SISMD & NEMR \\
\hline NEMO & $\mathbf{- 0 . 8 0}$ & 0.2 & & $-0.17^{\mathrm{a}}$ & $\mathbf{0 . 3 6}$ \\
NEMD & $\mathbf{0 . 4 8}$ & & $-0.06^{\mathrm{b}}$ & & -0.14 \\
SISML & $-0.08^{\mathrm{c}}\left(0.07^{\mathrm{d}}\right)$ & & & $\mathbf{0 . 3 5}$ \\
\hline
\end{tabular}

${ }^{\text {a }}$ Correlation is between demise of the SISM and onset of the following NEM season.

${ }^{\mathrm{b}}$ Correlation is between onset of the SISM and demise of the preceding NEM season.

${ }^{c}$ Correlation is between length of the SISM and length of the following NEM season.

${ }^{\mathrm{d}}$ Correlation is between length of the SISM and length of the preceding NEM season.

season to five days postonset (Fig. 6f). The eastwardflowing south equatorial counter current near the equator is well established at the time of the onset of the NEM (Fig. 6h) but evolves from a weaker current five days prior to onset (Fig. 6g) when the anomalies are westerly to a stronger current five days postonset (Fig. 6i) when the anomalies are eastward.

In Fig. 7, we show a similar composite of the upperocean variables as Fig. 6 but centered around the demise date of NEM. In contrast to the onset date composites (Fig. 6), we find that the wind stress has reversed along the Somali coast to southwesterly (Fig. 7b), ocean heat content has moved westward toward the western equatorial Indian Ocean (Fig. 7e), and the equatorial currents over the Indian Ocean have reversed to being easterlies (Fig. 7h) at the time of the demise of the NEM season. Here, we observe that the northeasterly wind stress along the western Indian Ocean and westerly wind stress over the equatorial Indian Ocean at the time of the demise (Fig. 7b) are getting weaker postdemise (Figs. 7c) relative to five days prior to the demise of the NEM season (Fig. 7a). Correspondingly, the anticyclonic curl in the Arabian Sea is also getting stronger postdemise relative to the period before the demise of the NEM season (Figs. $7 \mathrm{a}-\mathrm{c}$ ). The associated relative increase in the heat content (Fig. 7e) and easterly surface currents (Fig. 7h) over the equatorial western Indian Ocean postdemise of the NEM season is also observed (Figs. 7d and 7f). Similarly, the heat content also shows an evolution of its rise over the Arabian Sea and western equatorial Indian Ocean across the demise date of the NEM (Figs. 7d-f). The surface ocean currents also display an evolution of weakening (strengthening) easterlies over the eastern (western) equatorial Indian Ocean on either side of the demise date of the NEM (Figs. 7d-f).

\section{c. Interannual variability}

Table 2 shows the correlations of the onset and demise date variations with the corresponding variations in the length of the NEM season. From the correlations, it is apparent that the onset date variations of the NEM have a far stronger influence on the length of the NEM season variations than its demise date. The table suggests that later onset is likely to be associated with a shorter length of the NEM season or a longer NEM season is associated with earlier onset of the season. Similarly, Table 2 indicates that early or later onset with longer or shorter length of the NEM season are strongly related, respectively. Furthermore, Table 2 suggests that later onset of the NEM season is likely to be associated with NEM seasonal anomalies of rainfall that is wetter and surface temperature that is warmer, respectively. Likewise, a drier and colder NEM season is likely to be associated with early onset years (Table 2). These are very useful linear relationships as monitoring the onset of the NEM season in real time can provide a provisional outlook for the ensuing NEM season through these linear relationships.

The demise date variations, however, do not seem to have a statistically significant relationship with the seasonal anomalies of rainfall and surface temperature of the NEM season. However, the demise date variations have a significant influence on the preceding NEM seasonal length (Table 2), with later or early demise of the NEM season associated with a longer or shorter length of the NEM season, respectively. It may be stated that, given the correlations in Table 2, the variations in the onset and demise date of the NEM season influence the seasonal length variations independently.

Table 2 also indicates that correlations of the onset, demise, and length of SISM have an insignificant relationship with the corresponding variations of the demise of the preceding NEM season, onset of the following NEM season, and length of the following NEM season, respectively. In other words, we find no evidence of the memory of the Indian monsoon hydroclimate variations persisting from one season to the next, at least in the metrics that define their seasonal lengths. 


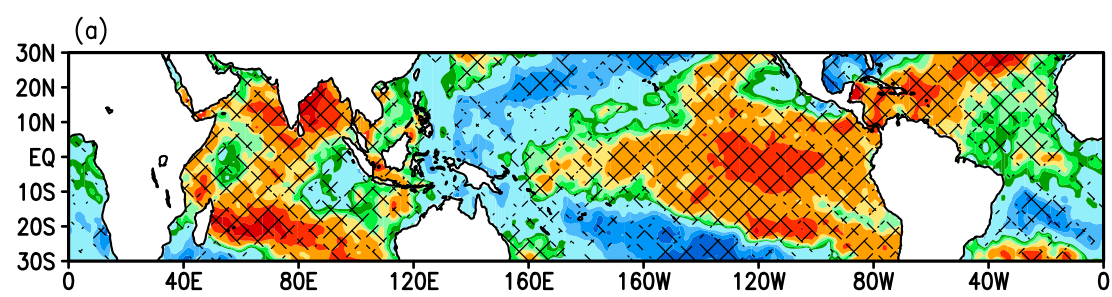

(b)

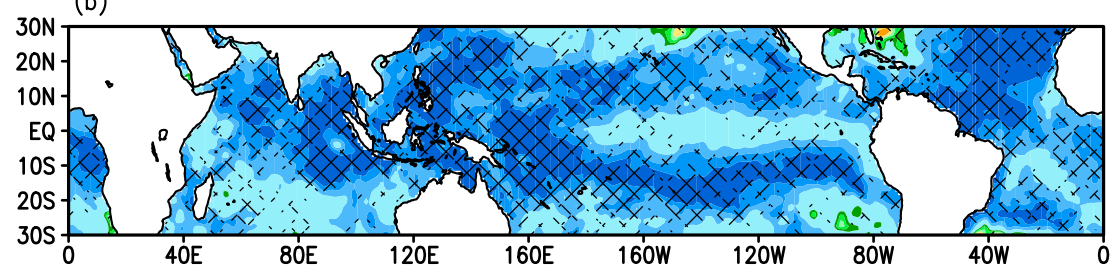

(c)
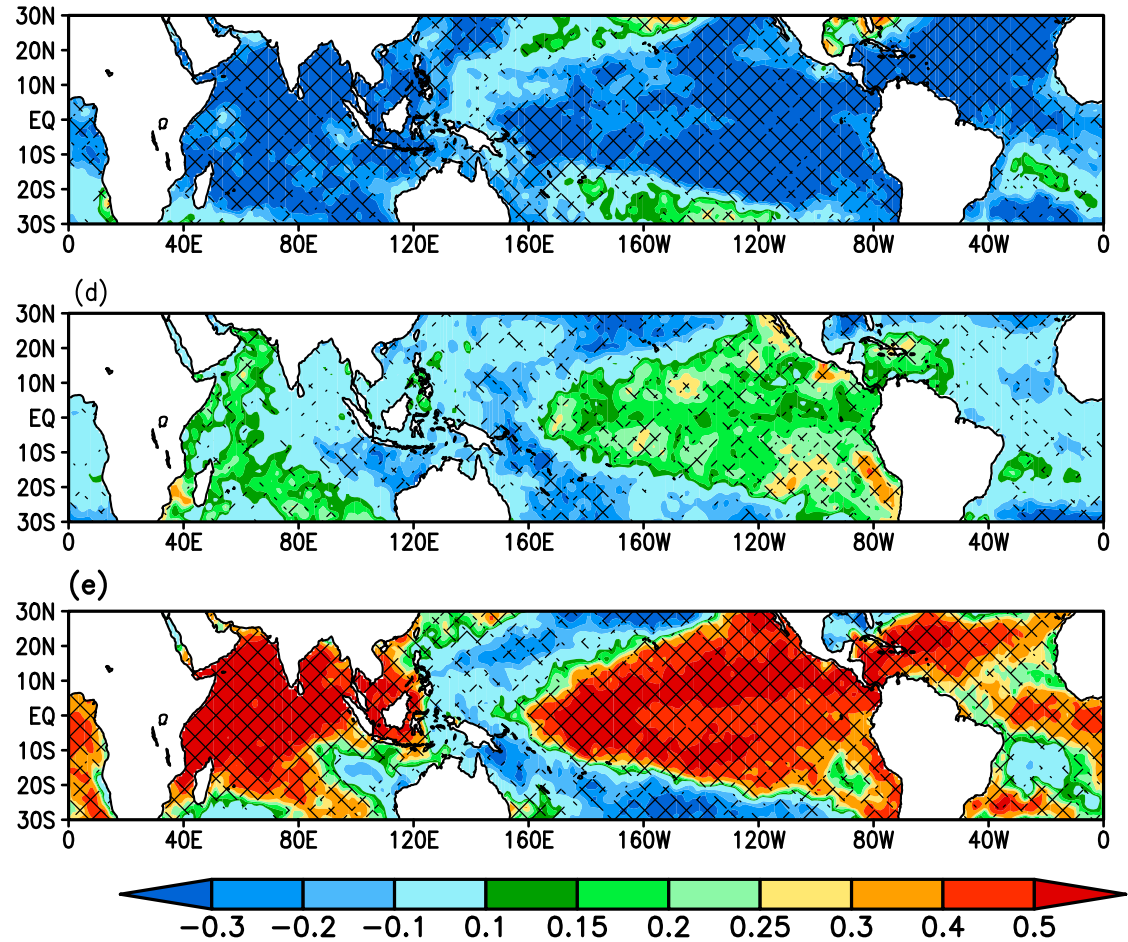

FIG. 8. The correlation of NDJ mean SST anomalies with (a) onset date, (b) demise date, (c) length, and seasonal mean (d) rainfall and (e) surface temperature anomalies of the NEM season. Significant values at $90 \%$ confidence interval according to bootstrap method are hashed.

The correlations of the onset of the NEM season with global tropical seasonal mean November-January (NDJ) SST in Fig. 8 show significant positive correlations over the tropical Indian, Pacific, and Atlantic Oceans. The dominant ENSO variations in the tropical Pacific and its contemporaneous correlations with tropical Indian and Atlantic Oceans is noted in this panel and in the subsequent panels of Fig. 8. The correlations in Fig. 8a suggest that warm or cold ENSO phases are associated with later or early onset of the
NEM season, respectively. Similarly, correlations of the demise date of the NEM season with NDJ mean global tropical SST is indicated in Fig. 8b. Here, unlike Fig. 8a, the correlations in the Niño-3.4 region is statistically insignificant. This is not surprising because the demise of the NEM season is in the boreal spring season when ENSO variations are usually at their weakest. However, the negative correlations over the eastern Indian Ocean and over the western Pacific Ocean are statistically significant (Fig. 8b). These negative correlations 
suggest, for example, that warm NDJ SST anomalies in these regions are associated with the early demise of the NEM season. Likewise, the negative correlations over the tropical oceans with the total length of the NEM season suggest, for example, that warm tropical oceans entail a shorter length of the NEM season (Fig. 8c).

The seasonal rainfall anomaly of the NEM season, however, shows a slight but statistically significant positive correlation with the eastern tropical Pacific SST, which suggests that warm or cold SST anomalies in this region are associated with surplus or deficit NEM seasonal rainfall anomalies (Fig. 8d), respectively. In other words, the shortened or lengthened NEM seasons with warm or cold SST anomalies in the tropical eastern Pacific Ocean can give rise to corresponding excess or deficit seasonal rainfall anomalies, when the relative daily rain rate increases or decreases, respectively. A comparison of the distribution of daily rainfall between these anomalous wet and dry NEM seasons do not suggest a systematic change in the daily rain rates during the rainy periods of October, November, and December of the NEM season (not shown). Therefore, the correlations in Fig. 8d suggest that excess or deficit seasonal rainfall anomalies of the anomalous NEM seasons are created by the reduction or increase of dry days in January, February, and March by the shortening or the lengthening of the NEM season, respectively. Figure 8d also reveals the fact that the positive or negative Indian Ocean dipole mode is associated with an increase or decrease in the seasonal rainfall anomaly of the NEM season (Fig. 8c), respectively.

The warm or cold seasonal surface temperature anomalies of the NEM are strongly associated with warm or cold tropical ocean SST anomalies (Fig. 8e), respectively. Figure 8 suggests that the anomalous warming of the surface temperature over the NEM domain, say, during a warm ENSO event, would delay the onset by shifting the inflection point in the cumulative anomaly curve to be later in the year and similarly curtail the length and accelerate the demise of the NEM season.

These relationships have been highlighted in Dimri et al. (2016). They indicate that in wet relative to dry NEM years, there is a southward movement of the subtropical westerly jet at $200 \mathrm{hPa}$ and weak anomalous cyclonic flow persists at lower levels over and across the Indian subcontinent, which make it conducive for the genesis and westward propagation of the western disturbances over the NEM region. In Figs. 9a-c, we have regressed the NDJ seasonal anomalies of $200-\mathrm{hPa}$ winds and geopotential height, $850-\mathrm{hPa}$ winds and geopotential height, and the MSLP on the length of the NEM season. We find from Fig. 9 that the variability of the length of the NEM season has a similar teleconnection as pointed in Dimri et al. (2016). For example, Fig. 9a suggests that longer NEM seasons (related with drier NEM seasons; see Table 2) are associated with weaker westerly anomalies at $200 \mathrm{hPa}$ and corresponding lower geopotential heights over and across the Indian subcontinent. Similarly, Fig. 9b suggests that at $850 \mathrm{hPa}$, longer and drier NEM seasons are associated with anticyclonic flow and slightly higher geopotential heights over India. Similarly, Fig. 9c shows that the longer and drier NEM seasons are associated with slightly higher MSLP over India.

\section{d. Comparison with other indices}

In contrast to the NEM, there are several studies that have attempted to define the onset and demise of the SISM based on dynamic indices (e.g., Koteswaram 1958, Ananthakrishnan et al. 1968; Krishnamurti and Ramanathan 1982; Webster and Yang 1992; Wang et al. 2001, 2009) and thermodynamic indices (e.g., Ananthakrishnan and Soman 1988; Yanai et al. 1992; Fasullo and Webster 2003; Janowiak and Xie 2003; Noska and Misra 2016). Obviously, the SISM being the primary wet season has drawn more attention for defining its season. Similarly, in other monsoon regions, the wettest season has been exclusively targeted to define the season in a variety of ways (e.g., Xu et al. 2004; Hung and Yanai 2004; Kajikawa et al. 2010; Liebmann et al. 2007; Fitzpatrick et al. 2015). We are unsure of the efficacy of many of these definitions of the monsoon onset and demise to detect secondary wet seasons of the region because of their focus on the wettest season of the year. For example, we have shown in this paper that diagnosing the inflection points in the cumulative anomaly curve based on rainfall to define the onset and demise of the NEM season is inappropriate, while it is very effective in diagnosing the onset/demise of the SISM (Noska and Misra 2016). Furthermore, some of these indices are based on empirical thresholds. For example, Ramage (1971) attempted to provide a universal index for onset of monsoons by suggesting that, at onset, the wind should exceed $3 \mathrm{~m} \mathrm{~s}^{-1}$ and the wind direction should shift by at least $120^{\circ}$ and persist for at least $40 \%$ of the time in the month of its onset. A few of the definitions of onset/demise are complicated. For example, Fasullo and Webster (2003) defined the onset of the SISM based on when the normalized vertically integrated moisture transport over the Arabian Sea exceeds zero. This method, although is objective and was demonstrated to be effective, requires several analyzed fields (e.g., humidity, winds, at several pressure levels and surface pressure) to compute the vertically integrated moisture transport. Such analysis, especially related to humidity, is often found to be biased 

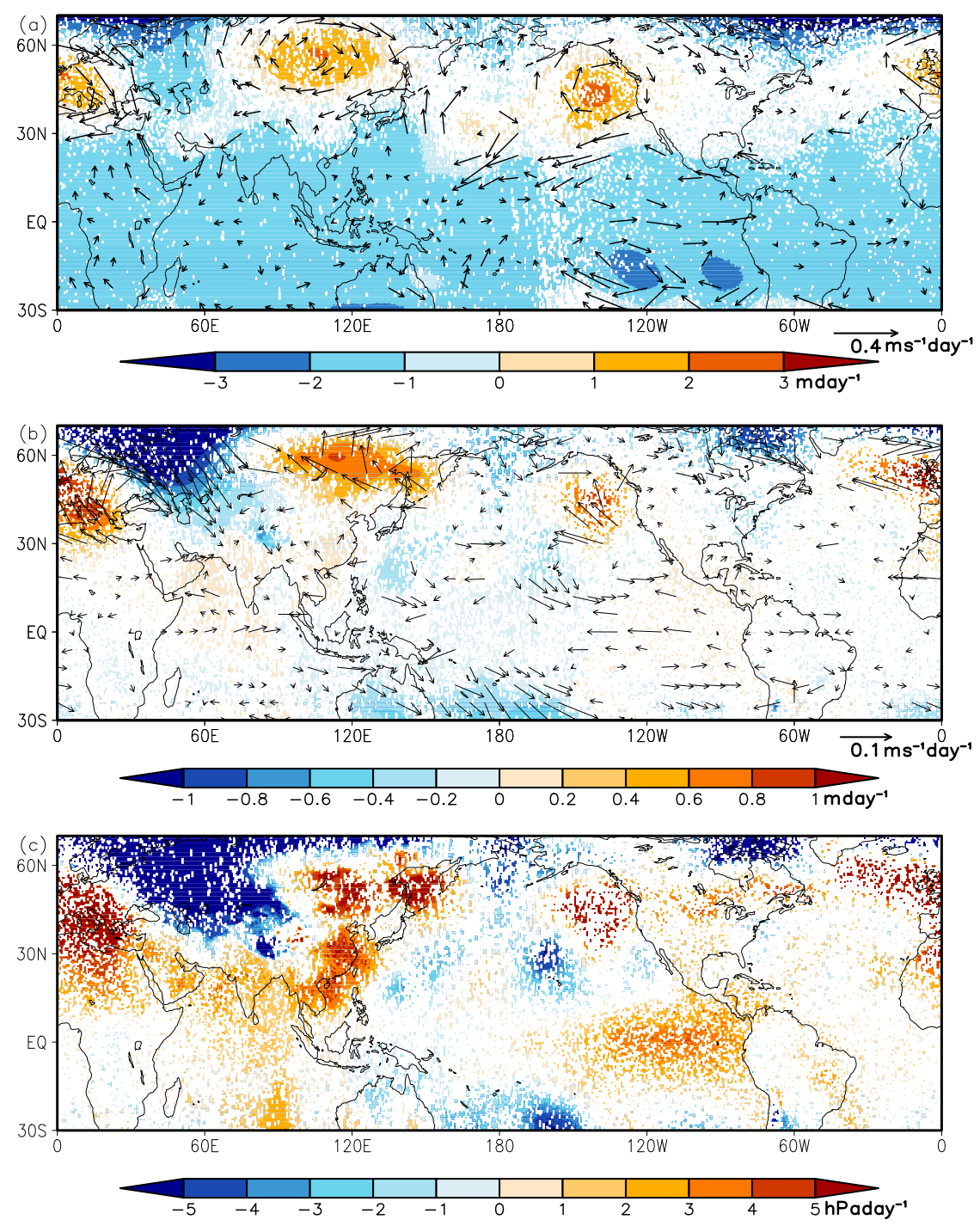

FIG. 9. The regression of (a) 200-hPa geopotential heights $\left(\mathrm{m} \mathrm{day}{ }^{-1}\right)$ and winds $\left(\mathrm{m} \mathrm{s}^{-1} \mathrm{day}^{-1}\right)$, (b) $850-\mathrm{hPa}$ geopotential heights $\left(\mathrm{m} \mathrm{day}^{-1}\right)$ and winds $\left(\mathrm{m} \mathrm{s}^{-1} \mathrm{day}^{-1}\right)$, and (c) MSLP $\left(\mathrm{hPa} \mathrm{day}^{-1}\right)$ on the length of the NEM season. Significant values at $90 \%$ confidence interval according to bootstrap method are shown.

(Lorenz and Kunstmann 2012) and could also make the operational monitoring of the index difficult.

In this study, we have proposed a definition for the onset and demise of the secondary wet season in the annual cycle of the Indian monsoon, namely, the NEM season. The proposed definition is simple to implement from a relatively easily available, single variable of surface temperature. As pointed out earlier, rainfall is not the correct metric to use for the NEM season owing to its strong interannual variations (Table 1). Based on this discussion, our proposed definition for the NEM season based on surface temperature can be argued to have a broader appeal to detect the secondary wet seasons in the annual cycle of other monsoon regions.

In Fig. 10, we have compared the seasonal rainfall based on the fixed length of the OND season over the NEM region with the seasonal rainfall from a varying length of the NEM season as defined in this paper. It is apparent from the figure that the fixed OND season systematically underestimates the accumulated seasonal rainfall relative to the varying length of the season. The climatological seasonal mean rainfall for the fixed OND season is $201.77 \mathrm{~mm}$, whereas it is $391.05 \mathrm{~mm}$ for the varying length of the NEM season. Furthermore, the correlation between the two estimates of the seasonal 


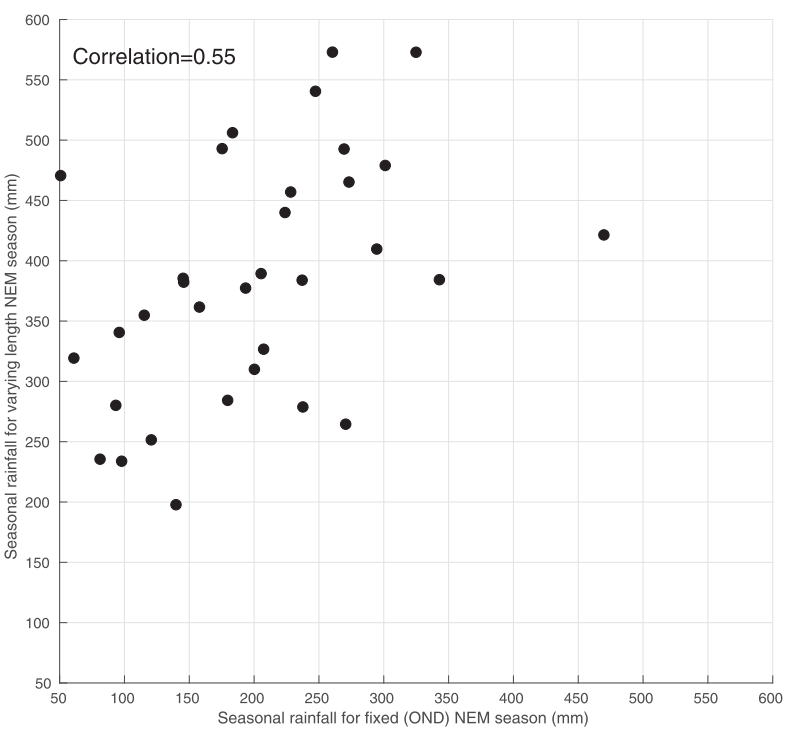

FIG. 10. The scatter of fixed OND and variable-length NEM seasonal rainfall $(\mathrm{mm})$ over the NEM region. The climatological seasonal mean OND rainfall is $201.17 \mathrm{~mm}$ and that for varying length of the NEM season is $391.05 \mathrm{~mm}$. The correlation between the two estimates of NEM seasonal rainfall is indicated in the legend.

rainfall is 0.55 (significant at $99 \%$ confidence interval according to $t$ test).

\section{Conclusions}

In this study, we introduce an objective definition to the onset and demise of the northeast Indian monsoon (NEM), a secondary wet season of the Indian monsoon annual cycle. This definition is based on the seasonal variation of the surface temperature over the land surface of the NEM domain, which includes the provinces of Tamil Nadu, Rayalseema, and Andhra Pradesh. We believe that our proposed definition of the NEM season provides a viable alternative to the traditional definition of the season for the following reasons:

1) The traditional definition of the NEM season tied to three calendar months [October-December (OND)] does not account for the variability in the length of the season of NEM, which is significant.

2) The OND season for NEM is based on a regional distributions of rainfall (over three provinces of India; namely, Tamil Nadu, Rayalseema, and Andhra Pradesh), which is not representative of the heterogeneous distribution of rainfall across the rest of India. Alternatively, the regional average of surface temperature over the NEM domain closely follows that of the corresponding all-India average.

3) The traditional definition of the NEM season, which is based on rainfall of the OND season, sometimes overlaps with the demise of the southwestern Indian summer monsoon (SISM), which consequently affects the estimate of the NEM seasonal rainfall.

4) Using NEM seasonal rainfall is not recommended for defining the season as its coefficient of variation is nearly $30 \%$ (for fixed OND season) to $45 \%$ (for varying length of the season) compared to using surface temperature, which has a coefficient of variation of about $4 \%$ (for fixed OND season) to 1\% (for varying length of the season). As a consequence, it is difficult to estimate the seasonal climatology of the NEM rainfall, especially from a small sample of years in comparison to surface temperature.

5) Human mortality of children (under five years) and the elderly is associated with exposure to cold temperatures during the NEM season. Furthermore, the incidence of cerebrovascular and respiratory diseases increases in the NEM season. Similarly, the cultivation of rice (which is one of the main crops grown in the NEM season in India) is sensitive to surface temperature, which consequently impacts the food security of the region. Therefore, ignoring the seasonality of surface temperature and its variations in the definition of the NEM season is perilous.

The definition of the onset and demise of the NEM in this paper, which is based on surface temperature analysis, is objective. The inflection points are more sharply defined in the daily cumulative curve of the surface temperature with no ambiguity from year to year between the days of the demise of the preceding SISM and the onset of the following SISM. Furthermore, the defined NEM season encompasses the seasonal evolution of the rainfall over the southeastern provinces of India. In addition, the seasonal cycle of surface temperature and its interannual variations over the southeastern provinces as well as that averaged over all of India follow each other quite closely. The study clearly shows that the interannual variations of the length of the NEM season are significant. Therefore, this paper's definition of the onset and demise of the NEM will have a broader relevance for all of India.

The climatological onset and demise of the NEM is found to be 6 November and 13 March, respectively. The composite 850-hPa winds, wind stress, upper-ocean heat content, and surface ocean currents suggest a consistent evolution prior to and postonset and demise of the NEM over the western Arabian Sea and the equatorial Indian Ocean. Both of these regions are characterized by robust seasonal cycles with reversals of the lower-tropospheric wind and upper-ocean circulations.

The analysis of the interannual variations indicate that early onset of the NEM is related to longer NEM seasons. 
Likewise, later onset of the NEM is associated with shorter NEM seasons. Similarly, the early and later demise of the NEM is related to shorter and longer NEM seasons, respectively. However, the relationship of the onset variations with the length of the NEM season is much more robust than that of the demise with the length of the preceding NEM season. It is also shown that the SST anomalies in the tropical equatorial Pacific Ocean during the NDJ season are positively (and in a statistically significant way) correlated with the seasonal rainfall anomaly of the NEM season. It is also shown that anomalously wet or dry NEM seasons are also associated with reduced or increased length and later or early onset of the NEM season, respectively. In other words, anomalously wet or dry NEM seasons have reduced or increased number of dry days in the season, respectively. Last, it is shown that SST anomalies in the eastern equatorial Pacific are positively correlated with the NEM surface temperature anomalies over the Indian subcontinent.

In light of this paper's new definition for the NEM season, it would be interesting to reevaluate the predictability and fidelity of model predictions and simulations of the NEM. This is part of ongoing work that will be presented in the near future.

Acknowledgments. The authors acknowledge the editorial assistance provided by Mrs. Tracy Ippolito of the Center for Ocean-Atmospheric Prediction Studies, Florida State University. The authors gratefully acknowledge the financial support given by NASA Grants NNX17AG72G, NNX16AD83G, NSF Award 1606296, and the Earth System Science Organization, Ministry of Earth Sciences, government of India (Grant $\mathrm{MM} / \mathrm{SERP} / \mathrm{FSU} / 2014 / \mathrm{SSC}-02 / 002)$ to conduct this research under Monsoon Mission.

\section{REFERENCES}

Ananthakrishnan, R., and M. K. Soman, 1988: The onset of southwest monsoon over Kerala: 1901-1980. J. Climatol., 8, 283296, https://doi.org/10.1002/joc.3370080305.

_ , V. Srinivasan, A. R. Ramakrishnan, and R. Jambunathan, 1968: Synoptic features associated with onset of southwest monsoon over Kerala. India Meteorological Department Forecasting Manual Rep. 18.2, Vol. 4.

Basu, R., 2009: High ambient temperature and mortality: A review of epidemiologic studies from 2001 to 2008. Environ. Health, 8, 40, https://doi.org/10.1186/1476-069X-8-40.

Beal, L. M., V. Hormann, R. Lumpkin, and G. R. Foltz, 2013: The response of the surface circulation of the Arabian Sea to monsoonal forcing. J. Phys. Oceanogr., 43, 2008-2022, https:// doi.org/10.1175/JPO-D-13-033.1.

Bishwajit, G., S. Sarkar, M. A. Kpoghomou, H. Gao, L. Jun, D. Yin, and S. Ghosh, 2013: Self-sufficiency in rice and food security: A South Asian perspective. Agric. Food Secur., 2, 10, https:// doi.org/10.1186/2048-7010-2-10.
Carmichael, G. R., and Coauthors, 2009: Asian aerosols: Current and year 2030 distributions and implications to human health and regional climate change. Environ. Sci. Technol., 43, 58115817, https://doi.org/10.1021/es8036803.

Dhar, O. N., and P. R. Rakhecha, 1983: Foreshadowing northeast monsoon rainfall over Tamil Nadu, India. Mon. Wea. Rev., 111, 109-112, https://doi.org/10.1175/1520-0493(1983)111<0109: FNMROT $>2.0 . \mathrm{CO} ; 2$.

Dimri, A. P., T. Yasunari, B. S. Kotlia, U. C. Mohanty, and D. R. Sikka, 2016: Indian winter monsoon: Present and past. Earth Sci. Rev., 163, 297-322, https://doi.org/10.1016/j.earscirev.2016.10.008.

Eurowinter Group, 1997: Cold exposure and winter mortality from ischaemic heart disease, cerebrovascular disease, respiratory disease, and all causes in warm and cold regions of Europe. Lancet, 349, 1341-1346, https://doi.org/10.1016/ S0140-6736(96)12338-2.

Farrell, T. C., K. M. Fox, R. L. Williams, S. Fukai, and L. G. Lewin, 2006: Minimising cold damage during reproductive development among temperate rice genotypes. II. Genotypic variation and flowering traits related to cold tolerance screening. Aust. J. Agric. Res., 57, 89-100, https://doi.org/10.1071/AR05186.

Fasullo, J., and P. J. Webster, 2003: A hydrological definition of Indian monsoon onset and withdrawal. J. Climate, 16, 3200-3211, https://doi.org/10.1175/1520-0442(2003)016<3200a: AHDOIM $>2.0 . \mathrm{CO} ; 2$.

Fitzpatrick, R. G. J., C. L. Bain, P. Knippertz, J. H. Marsham, and D. J. Parker, 2015: The West African monsoon onset: A concise comparison of definitions. J. Climate, 28, 8673-8694, https://doi.org/10.1175/JCLI-D-15-0265.1.

Ghadirnezhad, R., and A. Fallah, 2014: Temperature effect on yield and yield components of different rice cultivars in flowering stage. Int. J. Agron., 2014, 846707, https://doi.org/ 10.1155/2014/846707.

Hung, C.-W., and M. Yanai, 2004: Factors contributing to the onset of the Australian summer monsoon. Quart. J. Roy. Meteor. Soc., 130, 739-758, https://doi.org/10.1256/qj.02.191.

Ingole, V., S. Juvekar, V. Muralidharan, S. Sambhudas, and J. Rocklöv, 2012: The short-term association of temperature and rainfall with mortality in Vadu Health and Demographic Surveillance System: A population level time series analysis. Global Health Action, 5, 44-52, https://doi.org/10.3402/ gha.v5i0.19118.

_ S. Kovats, B. Schumann, S. Hajat, J. Rocklöv, S. Juvekar, and B. Armstrong, 2017: Socioenvironmental factors associated with heat and cold-related mortality in Vadu HDSS, western India: A population-based case-crossover study. Int. J. Biometeor., 61, 1797-1804, https://doi.org/10.1007/ s00484-017-1363-8.

Janowiak, J. E., and P. Xie, 2003: A global-scale examination of monsoon-related precipitation. J. Climate, 16, 4121-4133, https:// doi.org/10.1175/1520-0442(2003)016<4121:AGEOMP>2.0.CO;2.

Kajikawa, Y., B. Wang, and J. Wang, 2010: A multi-time scale Australian monsoon index. Int. J. Climatol., 30, 1114-1120, https://doi.org/10.1002/joc.1955.

Koteswaram, P., 1958: The easterly jet stream in the tropics. Tellus, 10, 43-57, https://doi.org/10.3402/tellusa.v10i1.9220.

Kripalani, R. H., and P. Kumar, 2004: Northeast monsoon rainfall variability over south peninsular India vis-à-vis the Indian Ocean dipole mode. Int. J. Climatol., 24, 1267-1282, https:// doi.org/10.1002/joc.1071.

Krishna Kumar, K., K. Rupa Kumar, R. G. Ashrit, N. R. Deshpande, and J. W. Hansen, 2004: Climate impacts on Indian agriculture. Int. J. Climatol., 24, 1375-1393, https://doi.org/10.1002/joc.1081. 
Krishna Rao, P. R., and P. Jagannathan, 1953: Rainfall of Madras with special reference to Tamil Nadu and Rayalaseema. Memoirs of the India Meteorological Department, Vol. 30.

Krishnamurti, T. N., and Y. Ramanathan, 1982: Sensitivity of the monsoon onset to differential heating. J. Atmos. Sci., 39, 1290-1306, https://doi.org/10.1175/1520-0469(1982)039<1290: SOTMOT $>2.0 . \mathrm{CO} ; 2$.

_- J. Molinari, and H. L. Pan, 1976: Numerical simulation of the Somali jet. J. Atmos. Sci., 33, 2350-2362, https://doi.org/ 10.1175/1520-0469(1976)033<2350:NSOTSJ > 2.0.CO;2.

_- B. Jha, P. J. Rasch, and V. Ramanathan, 1997: A high resolution global reanalysis highlighting the winter monsoon. Part I, reanalysis fields. Meteor. Atmos. Phys., 64, 123-150, https:// doi.org/10.1007/BF01029689.

Krishnan, A., 1984: An analysis of trends in the rainfall and droughts occurring in the southwest monsoon and northeast monsoon systems in the southern peninsular India. Mausam, 35, 379-386.

Kumar, P., K. R. Kumar, M. Rajeevan, and A. K. Sahai, 2007: On the recent strengthening of the relationship between ENSO and northeast monsoon rainfall over South Asia. Climate Dyn., 28, 649-660, https://doi.org/10.1007/s00382-006-0210-0.

Liebmann, B., S. J. Camargo, A. Seth, J. A. Marengo, L. M. V. Carvalho, D. Allured, R. Fu, and C. S. Vera, 2007: Onset and end of the rainy season in South America in observations and the ECHAM 4.5 atmospheric general circulation model. J. Climate, 20, 2037-2050, https://doi.org/10.1175/JCLI4122.1.

Lorenz, C., and H. Kunstmann, 2012: The hydrological cycle in three state-of-the-art reanalyses: Intercomparison and performance analysis. J. Hydrometeor., 13, 1397-1420, https://doi.org/ 10.1175/JHM-D-11-088.1.

Noska, R., and V. Misra, 2016: Characterizing the onset and demise of the Indian summer monsoon. Geophys. Res. Lett., 43, 45474554, https://doi.org/10.1002/2016GL068409.

Pan, Y. H., and A. Oort, 1990: Correlation analyses between sea surface temperature anomalies in the eastern equatorial Pacific and World Ocean. Climate Dyn., 4, 191-205, https:// doi.org/10.1007/BF00209521.

Pandey, P., and D. K. Tiwari, 2012: Modern techniques and agronomic packages for hybrid rice cultivation in India. Adv. Agric. Bot., 4, 17-21, http://aab.bioflux.com.ro/docs/ AAB_2012.4.17-21.pdf.

Raj, Y. E. A., and S. M. Jamadar, 1990: Normal dates of onset and withdrawal of southwest and northeast monsoons over the southern peninsula. Vayu Mandal, 20, 76-84.

Rajeevan, M., C. K. Unnikrishnan, J. Bhate, K. Niranjan Kumar, and P. P. Sreekala, 2012: Northeast monsoon over India: Variability and prediction. Meteor. Appl., 19, 226-236, https:// doi.org/10.1002/met.1322.

Ramage, C. S., 1971: Monsoon Meteorology. Vol. 15. Academic Press, $296 \mathrm{pp}$

Ramaswamy, C., 1972: The severe drought over Tamil Nadu during the retreating monsoon period of 1968 and its association with anomalies in the upper level flow pattern over the Northern Hemisphere. Indian J. Meteor. Geophys., 23, 303-316.

Randolph, S. E., and D. J. Rogers, 2010: The arrival, establishment and spread of exotic diseases: Patterns and predictions. Nat. Rev. Microbiol., 8, 361-371, https://doi.org/10.1038/ nrmicro2336.

Rodwell, M. J., 2005: Monsoon internal dynamics. The global monsoon system: Research and forecast, World Meteorological Organization Rep. WMO/TD-1266, 326-341, https://www.wmo.int/pages/prog/arep/tmrp/documents/ global_monsoon_system_IWM3.pdf.

Saha, S., and Coauthors, 2010: The NCEP Climate Forecast System Reanalysis. Bull. Amer. Meteor. Soc., 91, 1015-1058, https:// doi.org/10.1175/2010BAMS3001.1.

Samui, R. P., M. V. Kamble, and J. P. Sabale, 2013: Northeast monsoon rainfall and agricultural production in Tamilnadu and Andhra Pradesh: I-Rainfall variability and its significance in agricultural production. Mausam, 64, 309-316, http://metnet.imd.gov.in/ mausamdocs/16428_F.pdf.

Schott, F. A., and J. P. McCreary Jr., 2001: The monsoon circulation of the Indian Ocean. Prog. Oceanogr., 51, 1-123, https:// doi.org/10.1016/S0079-6611(01)00083-0.

Siew, J. H., F. T. Tangang, and L. Juneng, 2014: Evaluation of CMIP5 coupled atmosphere-ocean general circulation models and projection of the Southeast Asian winter monsoon in the 21st century. Int. J. Climatol., 34, 2872-2884, https://doi.org/10.1002/ joc.3880.

Singh, N., and N. A. Sontakke, 1999: On the variability and prediction of rainfall in the post-monsoon season over India. Int. J. Climatol., 19, 309-339, https://doi.org/10.1002/(SICI)1097-0088(19990315) 19:3<309::AID-JOC361>3.0.CO;2-\#.

Sontakke, N. A., 1993: Fluctuations in NE monsoon rainfall over India since 1871. Advances in Tropical Meteorology, Tata McGraw-Hill, 149-158.

Sreekala, P. P., S. V. B. Rao, and M. Rajeevan, 2012: Northeast monsoon rainfall variability over south peninsular India and its teleconnections. Theor. Appl. Climatol., 108, 73-83, https:// doi.org/10.1007/s00704-011-0513-x.

Srinivasan, V., and K. Ramamurthy, 1973: Northeast monsoon. Comprehensive articles on selected topics, India Meteorological Department Forecasting Manual Rep. 18.4, Vol. 4.

Srivastava, A. K., M. Rajeevan, and S. R. Kshirsagar, 2009: Development of a high resolution daily gridded temperature data set (1969-2005) for the Indian region. Atmos. Sci. Lett., 10, 249-254, https://doi.org/10.1002/asl.232.

Tourre, Y. M., and W. B. White, 1995: ENSO signals in global upperocean temperature. J. Phys. Oceanogr., 25, 1317-1332, https:// doi.org/10.1175/1520-0485(1995)025<1317:ESIGUO >2.0.CO;2.

Wang, B., R. Wu, and K.-M. Lau, 2001: Interannual variability of Asian summer monsoon: Contrasts between the Indian and western North Pacific-East Asian monsoons. J. Climate, 14, 4073-4090, https://doi.org/10.1175/1520-0442(2001)014<4073: IVOTAS $>2.0 . \mathrm{CO} ; 2$

—, Q. Ding, and P. V. Joseph, 2009: Objective definition of the Indian summer monsoon onset. J. Climate, 22, 3303-3316, https://doi.org/10.1175/2008JCLI2675.1.

Webster, P. J., and S. Yang, 1992: Monsoon and ENSO: Selectively interactive systems. Quart. J. Roy. Meteor. Soc., 118, 877-926, https://doi.org/10.1002/qj.49711850705.

Xu, J., X. Gao, J. Shuttleworth, S. Sorooshian, and E. Small, 2004: Model climatology of the North American monsoon onset period during 1980-2001. J. Climate, 17, 3892-3906, https://doi.org/ 10.1175/1520-0442(2004)017<3892:MCOTNA > 2.0.CO;2.

Yanai, M., C. Li, and Z. Song, 1992: Seasonal heating of the Tibetan Plateau and its effects on the evolution of the Asian summer monsoon. J. Meteor. Soc. Japan, 70, 319-351, https://doi.org/ 10.2151/jmsj1965.70.1B_319.

Zubair, L., and C. F. Ropelewski, 2006: The strengthening relationship between ENSO and northeast monsoon rainfall over Sri Lanka and southern India. J. Climate, 19, 1567-1575, https://doi.org/10.1175/JCLI3670.1. 